Guest article on theory

\title{
Understanding health education, health promotion and public health
}

\author{
Kitty R. van Teijlingen ', Bhimsen Devkota ${ }^{2}$, Flora Douglas ${ }^{3}$, \\ Padam Simkhada ${ }^{4}$, Edwin R. van Teijlingen ${ }^{5}$ *
}

${ }^{1}$ University of Winchester, England, UK

${ }^{2}$ Faculty of Education, Tribhuvan University, Kathmandu

${ }^{3}$ The Robert Gordon University, Aberdeen, Scotland, UK

${ }^{4}$ The University of Huddersfield, England, UK

${ }^{5}$ Bournemouth University, Bournemouth Gateway Building (5th floor), St Paul's Lane, Bournemouth, BH8 8GP, United Kingdom

*Corresponding author: evteijlingen@,bournemouth.ac.uk; http://orcid.org/0000-0001-5523-

$\underline{8583}$

\begin{abstract}
Across the globe, there can be confusion about the difference between the concepts of health education, health promotion and, often also, public health. This confusion does not limit itself to the individual terms but also to how these terms relate to each other. Some use terms such as health education and health promotion interchangeably; others see them clearly as different concepts. In this theoretical overview paper, we have first of all outlined our understanding of these individual terms. We suggest how the five principles of health promotion as outlined by the World Health Organization (WHO, 1984) fit into Tannahill's (2009) model of three overlapping areas: (a) health education; (b) prevention of ill health; and (c) health protection. Our schematic overview places health education within health promotion and health promotion itself in the center of the overarching disciplines of education and public health. We hope our representation helps reduce confusion among all those interested in our discipline, including students, educators, journalists, practitioners, policymakers, politicians, and researchers.
\end{abstract}

Keywords: Education, health education, health promotion, health protection, Nepal, public health

\section{INTRODUCTION}

Health promotion is a fairly new concept in Nepal (Sharma et al., 2015). The Ministry of Health and Population first mentioned preventative health services and promotive health services in its 1991 National Health Policy and the first-ever national health promotion conference was organized in 2013 (Simkhada, van Teijlingen, \& Wasti, 2015, p. 223). Since it is such a new term, it is not uncommon for some to use terms like health education and health 
promotion interchangeably (Whitehead, 2004). Whilst others use terms such as health education and public health to mean more or less the same. For example, some government agencies dealing with the population's health are called Public Health departments, whilst in other countries, government agencies with a very similar remit are referred to as Health Education departments. At the same time, other people see these labels as clearly referring to different concepts. In the words of Tones (1996) "health education is not synonymous with health promotion" (p.13). An example of this would be the editors of the journal International Journal of Health Promotion and Education, who deemed it necessary to use both terms in the journal's name. Interestingly, Gupta, Shuman, Tavera, Kulldorff and Finkelstein (2005) combined 'education' and 'promotion' in using the expression 'health promotion education in an article on child health promotion. We like to add some clarity to the debate around the boundaries and overlap of these separate and overlapping concepts. We argue that the concepts of 'health education, 'health promotion,' and 'public health' are not the same.

The first thing to note is that all three terms have 'health' in common. The World Health Organization (WHO, 2021) defines health as: "A state of complete physical, mental, and social well-being and not merely the absence of disease or infirmity." In other words, it is not just about health. It is about reaching a fulfilling life (Tones, 1996). Before we highlight the different ways these concepts are interrelated, we outline our understanding of each concept. Secondly, it is worthwhile to define 'education' before considering the concept of health education. Education is defined as "The process of receiving or giving systematic instruction, especially at a school or university" (UK Dictionary, n.d.). In this definition, education is related to teaching and training and the process of learning. The definition which appears in the Journal of Community Medicine \& Health Education (JCMHE) is slightly broader, i.e. education is "the process of facilitating every individual to learn, to gain knowledge on various subjects, to develop certain skills, to develop values, ethics, beliefs and good habits that can play a vital role in the betterment of their family and ultimately community" (JCMHE, 2021). This notion of education bears a resemblance to the ideas of Freire (1972) in his book The Pedagogy of the Oppressed. Freire sees a liberating potential in education, i.e., helping people become reflective and active improvers of their lives, rather than passive consumers of education and accepting their oppressed status.

The following sections outline the concepts of public health, health education and health promotion in more detail.

\section{Public Health}

The oldest term of the three is probably public health and health promotion, the youngest of all. Health promotion is the umbrella term including health protection, health care and health promotion. Public health is defined as "the art and science of preventing disease, prolonging life and promoting health through the organized efforts of society" (Acheson, 1988). It appears in the title of the first major legislation in the UK (United Kingdom) 'The Public Health Act of 1848', in the Canadian Public Health Association of 1910, and Royal Society for Public Health (RSPH) established in 1856, and the scientific journal Public Health which has been in continuous publication since 1888. These are just a few examples of the use of the term Public Health. Although it is worth remembering that Public Health itself has had different names, public health in the UK has also been called 'social medicine' and 'community medicine' or 'population health'. The first public health department at a UK university was established by Professor John Ryle at the University of Oxford in 1943 and it was called the Institute of Social Medicine (Horton, 2013). Around that same time, we find the term 'Social Medicine' in $A$ 
Handbook of Social Medicine (Grundy, 1945). Seventy-five years ago, Kershaw (1946) used 'Public Health and Preventative Medicine' in his textbook An Approach to Social Medicine. He wrote that at the time, it referred to as "synonymous descriptions of the medical and social work carried out by the social group as a whole, whether the state or the local community, to promote the health of its members" (Kershaw, 1946, p. 198). Community medicine is often seen as a branch of medicine, also called community health which aims to improve people's health in a defined community. Over the past three decades, public health has become the more commonly used name in the UK and in many other English-speaking countries. Public health combines "prevention and promotion with the population as the target group with a societal focus" (George, 2019, p. 171).

In recent years, some have started to use the phrase 'New Public Health.' The New Public Health is a contemporary application of a broad range of evidence-based scientific, technological, and management systems implementing measures to improve the health of individuals and populations (Tulchinsky \& Varavikova, 2010).

\section{Health Promotion}

Health promotion became a more independent stream within traditional public health in the second half of the twentieth century. The key concept of health promotion, as highlighted by the WHO (1984), has five principles: (1) actively involves the population in everyday-life settings; (2) directed towards action on the causes (determinants) of ill-health; (3) uses five strategic approaches that aim to influences and effect change at the individual, community and organizational / policy levels, including education, information, community development and legislation; (4) public participation and empowerment; and (5) key roles played by health workers, particularly in primary health. This resulted in The Ottawa Charter for Health Promotion (Health \& Welfare Canada., 1986) which recognized that: "The fundamental conditions and resources for health are peace, shelter, education, food, income, a stable ecosystem, sustainable resources, social justice, and equity." Health promotion is considered to be distinct from the New Public Health "by emphasizing the wider social influences upon collective and individual health" (Mold \& Berridge, 2013, p. 13).

In order to illustrate how these five principles outlined by the WHO are interrelated, Tannahill (2009) has provided a model of health promotion in the mid-1980s which comprises three overlapping areas: (1) health education; (2) prevention of ill health; and (3) health protection (see Figure 1).

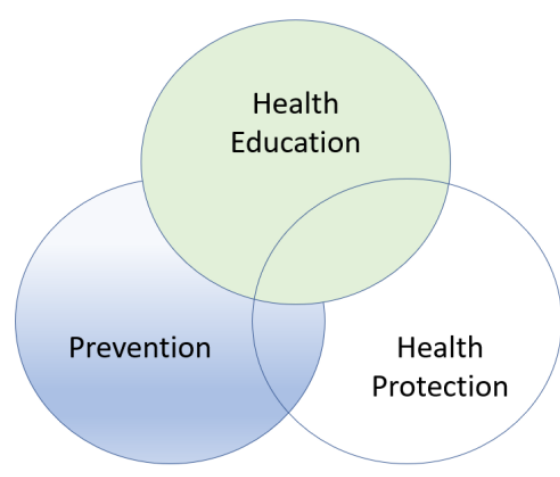

Figure 1. Interrelationship between health promotion and health education 


\section{Health Education}

We have put health education as third on the list, as it is one of the five health promotion action areas (as defined by the Ottawa Charter) and is one of the three contribution fields to health promotion in Figure 1. However, it is important to remember that health education dates back long before the late twentieth-century ideas around the health promotion concept developed. For some, health education grew out of the discipline of education. In this view, health education is a branch of education, in the same way, religious education, physical education, or science education are specialist areas within education. This view is highlighted in the following UK publication from half a century ago. In this Department of Education and Science (1968, p. vii) publication, health education focuses on school-based activities when it states: "Health education is concerned with a vast and varied field, touching many branches of science besides such subjects as history, geography and language; it involves every type of school, children, of all kinds, parents, teachers, all of us."

Downie, Fyfe, \& Tannahill (1994) offer a broader definition of health education as a "communication activity aimed at enhancing positive health and preventing or diminishing illhealth in individuals and groups, through influencing the beliefs, attitudes, and behavior of those with power and the community at large" (p.8). Similarly, Green and Kreuter (2005) define health education as "any planned combination of learning experiences designed to predispose, enable, reinforce voluntary behavior conducive to health in individuals, groups or communities" (p.7).

\section{Interrelated concepts}

MacDonald (1998) argues that health promotion must avoid the drawbacks of conventional health education; the latter includes increasing anxiety in people by teaching them about and raising awareness of risks in people's lives. According to MacDonald (1998), health promotion must reduce stress in people, "rather than increasing it, because of a perceived gap between health and actual lifestyle" (p.29). Tones (1996) mentions that health education is a key part of, but not the same as, health promotion. The former is necessary for the latter to achieve its goals successfully, but also that legislation and funding are essential for the success of health promotion. The WHO (2012) publication Health education: theoretical concepts, effective strategies and core competencies refer to health education "as a tool for health promotion."

Figure 2 illustrates the relationships between the overarching disciplines of education and public health and the more specific ones of health education and health promotion as we see them.

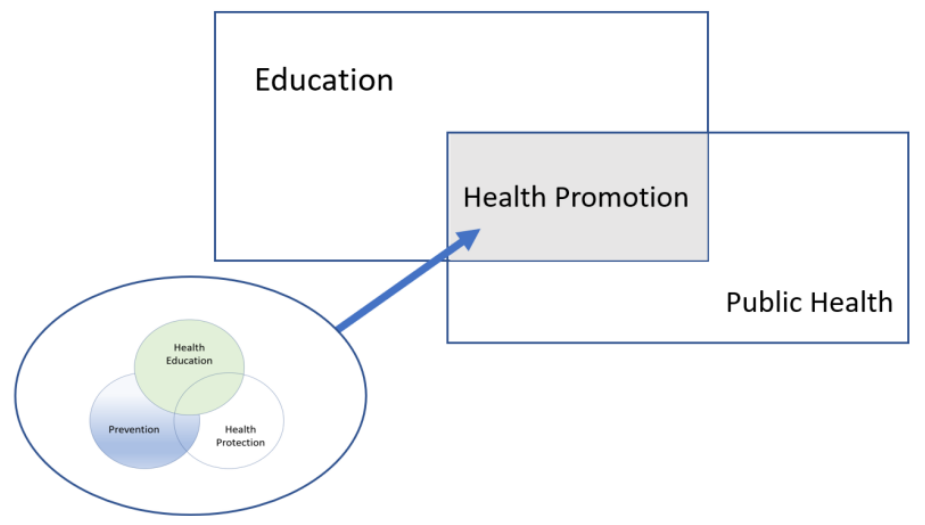

Figure 2. Health promotion linked to education and public health 
Fig. 2 above shows that Health Education is an important and integral part or sub-set of public health and health promotion. It is at the core of all educational disciplines relating to individual and community health. On the other hand, health promotion and public health go beyond the scope of health education to a more enabling environment, empowerment and policy options. They have inextricable linkages despite being blurred in their concepts and identities. Both health education and health promotion are planned and systematic processes that positively influence an individual's behavior, whereas health education is more voluntary (Green \& Tones, 2010; Green \& Kreuter, 2005). Health education involves voluntary changes in behavior through awareness, knowledge, skills, beliefs, attitudes, and values, whereas health promotion utilizes approaches that compel individuals to change their behaviors. Both health education and health promotion emphasized using a set of techniques from education to the community and work settings. Similarly, Green and Tones (2010) regard health promotion as the "critical conscience of public health". Others consider health education as a core and integral function of public health and health educators serve as key public health functionaries.

\section{Final thoughts}

In this global COVID-19 pandemic, the importance of Public Health has reached the attention of many. For those not working in the public health field, the different terms used can be confusing. It seems both appropriate and timely that we outline the different ideas behind the terms. The concept of health promotion is still not considered as a part of a broader public health approach in Nepal. Similarly, health education is being regarded by some as classroom activities among children. The plurality of interpretation of concepts without clear boundaries can be confusing and even problematic. We hope our analysis is of some assistance to students, practitioners, health managers, politicians, and researchers to help reduce some of the confusion. It should be recognized that the concepts of health promotion, public health and health education are still evolving, such as new public health, critical health promotion and critical health education.

\section{REFERENCES}

Acheson, D. (1988). Public health in England: The report of the Committee of Inquiry into the Future Development of the Public Health Function. London: HMSO.

Journal of Community Medicine \& Health Education [JCMHE]. (2021). About the Journal. Journal of Community Medicine \& Health Education. Retrieved from https://www.omicsonline.org/community-medicine-health-education.php.

Department of Education and Science. (1968). A handbook of health education, London: Her Majesty's Stationary Office.

Downie, R.S., Fyfe C., \& Tannahill A. (1994). Health promotion: models and values (reprint with corrections). Oxford: Oxford University Press.

Freire, P. (1972). Pedagogy of the oppressed. Harmondsworth: Penguin Books.

George, M. (2019). Public health-oriented healthcare systems: Need for a modified typology, The National Medical Journal of India, 32(3),171-174. Doi: https://doi.org/10.4103/0970-258X.278689

Green, L. W., \& Kreuter, M. W. (2005). Health programme planning: An educational and ecological approach $\left(4^{\text {th }}\right.$ ed.). New York: McGraw Hill 
Green, J., \& Tones, K. (2010). Health promotion: Planning and strategies ( $2^{\text {nd }}$ ed.). London: Sage

Grundy, F. (1945). A Handbook of social medicine. Luton: Gibb, Bamforth \& Co.

Gupta R. S., Shuman, S., Tavera, E. M., Kulldorff, M., \& Finkelstein, J. A. (2005). Opportunities for Health Promotion Education in Child Care. Pediatrics, 116(4), 499505. doi: https://doi.org/10.1542/peds.2005-0467

Health \& Welfare Canada. (1986). Achieving Health for All: A Framework for Health Promotion. Ottawa: Government of Canada. Retrieved from https://www.canada.ca/en/health-canada/services/health-care-system/reportspublications/health-care-system/achieving-health-framework-health-promotion.html accessed on Jan 2021.

Horton, R. (2013). Public health or social medicine? It matters. The Lancet, 382(3), S1-S105. doi: https://doi.org/10.1016/S0140-6736(13)62427-7

Kershaw, J. D. (1946). An approach to social medicine. London: Baillière, Tindall and Cox

MacDonald, T. H. (1998). Rethinking health promotion: A global approach. London: Routledge.

Mold, A., \& Berridge, V. (2013). The history of health promotion, In: L. Cragg, M. Davies, \& W. Macdowall (Eds.) Health Promotion Theory ( ${ }^{\text {nd }}$ ed.). Maidenhead: Open University Press, pp. 3-19.

UK Dictionary. (n.d.). Education. Retrieved from https://www.lexico.com/definition/education

Sharma, A., Tuladhar, G., Dhungel, A., Padmadharini, van Teijlingen, E., \& Simkhada, P. (2015). Health Promotion: A review of policies and practices in Nepal, Public Health Perspective Nepal, 5(2). Retrieved from https://www.phpnepal.org.np/publication/current-issue/featured-articles/113-healthpromotion-a-review-of-policies-and-practices-in-nepal

Simkhada, P.P., van Teijlingen, E., \& Wasti, S.P. (Eds.) (2015) The Dynamics of Health in Nepal. Wasti, S.P. et al. (eds.). Kathmandu, Nepal: Social Science Baha \& Himal Books.

Tannahill, A. (2009). Health promotion: The Tannahill model revisited. Public Health, 123(5), 396-399. doi: https://doi.org/10.1016/j.puhe.2008.05.021

Tones, K. (1996). The anatomy and ideology of health promotion: empowerment in context. In: A. Scriven \& J. Orme (Eds.), Health Promotion: Professional Perspectives, Houndsmills: Macmillan Press Ltd: 9-21. doi: https://doi.org/10.1007/978-1-349-24580-2_2

Tulchinsky, T. H., \& Varavikova, E. A (2010). What is the "New Public Health"? Public Health Review, 32(1), 25-53.doi: https://doi.org/10.1007/BF03391592

Whitehead, D. (2004). Health promotion and health education: advancing the concepts. Journal of Advanced Nursing, 47(3), 311-320. doi: https://doi.org/10.1111/j.13652648.2004.03095.x 
World Health Organization. Regional Office for Europe. ((1984 .Health promotion: a discussion document on the concept and principles: summary report of the Working Group on Concept and Principles of Health Promotion, Copenhagen, 9-13 July 1984. Copenhagen: WHO Regional Office for Europe. Retrieved from https://apps.who.int/iris/handle/10665/107835

World Health Organization. Regional Office for the Eastern Mediterranean. (2012). Health education: Theoretical concepts, effective strategies and core competencies: A foundation document to guide capacity development of health educators. Retrieved from https://applications.emro.who.int/dsaf/EMRPUB 2012 EN_1362.pdf.

World Health Organization. (2021). Constitution of the World Health Organization. Geneva: WHO. Retrieved from: https://apps.who.int/gb/bd/PDF/bd47/EN/constitutionen.pdf?ua $=1$ 